\title{
LETTER
}

\section{Is routine autopsy in the intensive care unit viable? Authors' response}

\author{
Greet Yvonne Agnes De Vlieger, Elien Marie Jeanne Lia Mahieu and Wouter Meersseman* \\ See related letter by Girbes and Zij|stra, http://ccforum.com/content/14/3/425 and research by De Vlieger et al., http://ccforum.com/content/14/2/221
}

In the previous issue of Critical Care, we read with interest the reaction of Girbes and Zijlstra [1] to our article on the role of autopsy in critically ill patients [2]. The authors believe that the declining autopsy rate is acceptable since current medicine is based on guidelines. However, guidelines can be driven by findings in large series of autopsies. Candida pneumonia occurs rarely in patients in whom Candida species are isolated in respiratory specimens; this argues against treating mechanically ventilated patients with antifungal drugs solely on the basis of a positive respiratory culture [3]. The recently published guidelines of the Infectious Diseases Society of America are also against such a practice [4].

We are convinced that the sensitivity and specificity of autopsy decline because of a lack of routine. Only pathologists who frequently perform autopsies are able to reveal rare pathologies. Good sensitivities and specificities of a test can be achieved only with a large sample size. Moreover, the autopsies should be performed in the presence of the treating intensivist in order to improve the yield of the autopsy. Innovative techniques also arise and might improve diagnostic performance (for example, molecular analysis in sudden death [5]).

Finally, we believe that autopsy is not always a nonrandom sample from a small selected population. Roosen and colleagues [6] found an autopsy rate of $93 \%$ in the medical intensive care unit. Some firm conclusions were drawn (for example, fungal pneumonia is among the most frequently missed diagnoses in a medical intensive care unit) [6]. Although we do realize that such high autopsy rates belong to the past rather than to the future, we think that autopsies remain valuable even in the era of modern medicine.

\section{Competing interests}

The authors declare that they have no competing interests.

Published: 29 July 2010

\section{References}

1. Girbes A, Zijlstra J: Is routine autopsy in the intensive care unit viable? Crit Care 2010, 14:425.

2. De Vlieger GY, Mahieu EM, Meersseman W: Clinical review: What is the role for autopsy in the ICU? Crit Care 2010, 14:221.

3. Meersseman W, Lagrou K, Spriet I, Maertens J, Verbeken E, Peetermans WE, Van Wijngaerden E: Significance of the isolation of candida species from airway samples in critically ill patients: a prospective autopsy study. Intensive Care Med 2009, 35:1526-1531.

4. Pappas P, Kauffman C, Andes D, Benjamin D, Calancra T, Edwards J, Filler S, Fisher J, Kulleberg B, Ostrosky-Zeichner L, Reboli A, Rex J, Walsh T, Sobel J: Clinical practice guidelines for the management of candidiasis: 2009 update by the Infectious Diseases Society of America. Clin Infect Dis 2009, 48:503-535.

5. Ackerman MJ, Tester DJ, Porter CJ, Edwards WD: Molecular diagnosis of the inherited long-QT syndrome in a woman who died after near-drowning. NEngl J Med 1999, 341:1121-1125.

6. Roosen J, Frans E, Wilmer A, Knockaert D, Bobbaers H: Comparison of premortem clinical diagnoses in critically ill patients and subsequent autopsy findings. Mayo Clin Proc 1999, 27:299-303.

doi:10.1186/cc9194

Cite this article as: De Vlieger GYA, et al: Is routine autopsy in the intensive care unit viable? Authors' response. Critical Care 2010, 14:433.
*Correspondence: wouter.meersseman@uzleuven.be

Department of General Internal Medicine, Medical Intensive Care Unit, University Hospital Gasthuisberg, Herestraat 49, 3000 Leuven, Belgium 